\title{
Intellectually gifted individuals' Career Choices and Work Satisfaction: A descriptive study
}

\author{
Roland S Persson \\ School of Education \& Communication \\ Jonkoping University \\ P.O. Box 1026 \\ SE-55111 Jonkoping, Sweden \\ pero@hlk.hj.se
}

Publication details:

Persson, R. S. (2009). Intellectually gifted individuals' career choices and work satisfaction: a descriptive study. Gifted and Talented International, 24(1), 11-24, 


\begin{abstract}
This study set out to study which career path a group of intellectually gifted individuals chose, if any. How did they actually like their work, and which were the reasons for satisfaction or dissatisfaction with their chosen career? In all, 287 Mensa members (216 men and 71 women) constituted the research group. Average age was 34.4 years $(S D=8.8)$. All had obtained IQ scores equal to or higher than the $98^{\text {th }}$ percentile. The study was designed as a survey operationalized as an Internet-based questionnaire using the SPSS Dimensions software. A shortened version of the Work and Life Attitudes Survey (Warr, Cook \& Wall, 1979) was included as part of the questionnaire. Quantitative data were analyzed as dispersions within the research group whereas qualitative data were content-analyzed using the so-called VSAIEEDC Model. Results show that participants tended to pursue careers mainly in Technology, Science and Social Work and to a lesser degree in Practical and Aestethic work. For all these fields work satisfaction was shown to be average. For individuals choosing to start their own company and/or who end up in leading managerial positions, however, satisfaction with work and career is very high. Possible reasons for these difference between subgroups in the sample are focused, and in conclusion a possible way forward to improve work satisfaction for intellectually gifted individuals at work, where needed, is discussed.
\end{abstract}




\section{Introduction}

Increasing amounts of research (eg. Schlosser, 2001; Yewchuk, Äystö \& Schlosser, 2001) and literature more or less anecdotal in nature (eg. Lewis, 1997) is devoting time and effort to explain success or lack thereof; not only in the field of high ability studies but perhaps even more so in general management and human resource studies. Prompting such research is of course a desire to find factors which could more or less predict success or expertise which are assumed to facilitate or even cause it (van der Heijden, 2000). However, while the somewhat nebulous meaning of "success" is not necessarily tied to giftedness but more often to marketability (Adler, 1985; Hamlen, 1991), it is not unusual to argue that developing gifted education and special provision for the gifted and talented population is important for success or alternatively continued societal welfare and development (eg. Wilms, 1986).

Singapore researchers Teo and Quah (1999) makes the following observation: "The Gifted Education Program (GEP) in Singapore has been in existence for more than a decade. But few of its graduates have made exceptional contributions to Self or the nation; a nation with hardly any natural resources and which relies a great deal on its human resources for surviving in a competitive world" (p. 23). It would seem that controlling desired success as based on giftedness is not a simple and straightforward issue, even if there are examples also of more successful such endeavors (Arnold, 1995). To my knowledge, there are no studies done so far on intellectually gifted individuals and how they experience their place of work and why. A database search using Google Scholar and Academic Search Elite search engines on key words "gifted, work, job, management" gave no useful results (search performed on July $27^{\text {th }}, 2008$ ).

There are reasons to believe, however, that the intellectually gifted individuals do not readily fit into the rigid organizational cultures or routine work so typical of modern rationalistic society (Ritzer, 1992), and that their feeling of satisfaction — and by implication also their productivity (or success)-- is closely tied to experiencing challenge, freedom and variety (cf. Streznewski, 1999; 
Locke, 1984). Shaughnessy and Manz (1991), for example, made the observation that "typically, artists, musicians and writers find their life's work outside bureaucratic institutions, which may hamper their creativity and originality" (p. 98). Furthermore, David Willings - a personnel management expert and scholar-offers a few typical statements as told by senior managers of intellectually gifted individuals as part of the workforce: "Why do we hire these intellectuals? They're no damned use. They don't fit in. They cause trouble", and further "we had a very gifted young chap. He came up with two ideas which we have unashamedly stolen. But he never learned to follow normal procedure. Couldn't fill out a PY34 form to save his life. He left us after seven months and I think it for the best" (as quoted in Streznewski, 1999; p. 132).

This study therefore seeks the answer to the following questions:

- In a group of intellectually gifted individuals, which career path did they choose if any?

- How did this intellectually gifted group of individuals actually like their work?

- Which were their reasons for satisfaction or dissatisfaction with their chosen profession?

\section{Method}

A survey design operationalized by an Internet-based questionnaire seemed the most efficient way of reaching the participants. The Swedish branch of Mensa volunteered to participate in the study. In discussing administration with their local representative as well as with the national Mensa Directorate, it was decided that a web-administered questionnaire was the most convenient and to members also the most appealing way of answering questions. Therefore, a questionnaire was constructed using SPSS Dimensions (Statistical Package for the Social Sciences, 2007) which was made available on-line for a little more than a month (mid-May until beginning of July 2007).

Mensa members where invited to participate by a brief article in Legatus Mensae (Mensa's newsletter for members only) outlining the research and providing the URL to finding the 
questionnaire. The Mensa Directorate also sent electronic mail to all members as a reminder. Research sample

The advantage of engaging Mensa is that their membership requirement is an authorized IQ-test (most often the Stanford-Binet) with a lowest resulting score of IQ131 (the $98^{\text {th }}$ percentile or higher). Since there are no standard identification procedures for giftedness in Sweden, where this research took place, and no official recognition of giftedness or gifted education at the present time, the Mensa group represents a both interesting and opportune high-IQ group of intellectually gifted individuals for the study. The criterion for participating is therefore the same as the criterion to become a member of Mensa: no participant has scored an IQ-test lower than IQ131 (or lower than the $98^{\text {th }}$ percentile), which in Gagné's (1993) understanding qualifies the members of the studied group as at least "moderately gifted". There are, however, distinctions made beyond this criterion, which is also reflected in the studied group. While Gagné proposes to divide IQgiftedness into the following levels: Basic (IQ115-117); Moderate (IQ125-130); Highly (IQ140150 ) and Extremely (IQ155-160), the choice was made in this research to ask respondents to report percentile scores. Not everyone had been tested by the same test battery, and not all were able to report their IQ-scores. But all could report their percentile score. Hence, three levels were distinguishable; continuing to use Gagné's nomenclature: $35 \%$ of the group may be characterized as moderately gifted $\left(98^{\text {th }}\right.$ percentile); $58 \%$ as highly gifted $\left(99^{\text {th }}\right.$ percentile $)$ and $7 \%$ as extremely gifted $\left(100^{\text {th }}\right.$ percentile $)$ as based on IQ scores alone.

In all, 614 individuals decided to fill in the questionnaire. However, of these 321 left the questionnaire unfinished (52\%). The reasons for this, I believe, is that a large number of the original participants $(52 \%)$ were frustrated with the questions. Some feedback was received from a few of these individuals, the reason mainly being one where respondents felt constrained by the format. They had more to say, but could not! Thus, 293 individuals remained and of these further six 
respondents had to be eliminated as extreme cases of little serious intent.

Hence, the studied intellectually gifted population of 287 participants has the following characteristics: The youngest participants are 18 years old and the oldest are 68 years of age (Range $=50)$. Mean age of the group is 34.4 years $(\mathrm{SD}=8.8)$. The studied group is heavily skewed towards men. Of the 287 participants $216(75 \%)$ were men, whereas only $71(25 \%)$ were women. This is a weakness in the design since men and women, as well as boys and girls, tend to exist under somewhat different conditions in regard to their giftedness and have somewhat different experiences (Kerr, 1994; Freeman, 1998).

Also, no control group was considered for this particular study, mainly due to its descriptive nature, but also for logistical reasons. A control group for comparison would have been an advantage, but was deemed not necessary.

\section{Instrumentation}

The questions pertaining to education and type of work were straight-forward and exploratory in nature. Questions were of three kinds (see Appendix 1): multiple choice per variable, scaled statements and free qualitative responses. Included in the questionnaire was an adapted and shortened version (11 items) of the Work and Life Attitudes Survey (Warr, Cook \& Wall, 1979). This version functioned well in the current research context and displayed high internal consistency: Alpha $=.90 ;$ Spearman-Brown Unequal Length $=.88$ and Guttman Split-Half Coefficient $=.88$. A principle component analysis was also employed trying the validity of the construct in a Swedish setting. This analysis showed the scale to be fairly uniform in its construction. Only one factormost likely interpreted as work satisfaction - could be extracted explaining $51 \%$ of the total variance.

The questionnaire was administered in Swedish. For the purpose of communicating results, however, everything pertaining to the study, including qualitative data, have been translated into 
English.

The questionnaire was also customarily subjected to a peer evaluation to check feasibility, appropriateness — both ethical and methodological—and content. Two reviewers were asked to comment: one fellow scientist and one exceedingly gifted individual representing the population to be studied. Remarks and comments were few, but wishes were expressed by the gifted representative that the questionnaire should yield space for written individual comments. This was heeded and a question allowing for free verbal response was added.

\section{Data security and research ethics}

Questions of data security and the protection of sensitive information were raised and settled. The resulting database was hosted at an designated secure and approved server. Only the researcher and system administrators had access to the database by password. However, in fulfillment of (Swedish) legal stipulations governing the handling of sensitive data the most important aspect of research ethics in this study is that the questionnaires are in fact truly anonymous. Personal information such as names, codes, social security numbers or addresses were not requested or in any way recorded. Therefore, the database as such contains untraceable anonymous data, which only make sense if analyzed in context and as trends.

\section{Manner of analyses}

Quantitative data were submitted to a simple, descriptive, frequency analysis focusing generally on dispersions within the researched group. The qualitative data as derived from respondents' free responses, were submitted to a traditional content analysis stringently following the so-called VSAIEEDC Model (for a thorough outline of the procedure confer Persson, 2006). 


\section{Results}

\section{Educational and professional background}

The research group is in general a highly educated group with an emphasis on traditional academic training: $74.2 \%$ have degrees and/or training from tertiary education, whereas $25.8 \%$ either have no training beyond secondary school or have obtained some other kind of training (Table 1). Of these $62(21.6 \%)$ have multiple degrees and/or several types of training (Table 2). This should be compared with the entire Swedish general population of which approximately $19 \%$ went on to some kind of tertiary education after secondary school (Statistics Sweden, 2007).

Table 1 about here

Table 2 about here

Respondents were also asked which their current full-time occupations were. Professions were categorized into related fields for a better overview (Table 3). Categories were broadly defined. To demonstrate the approximate distribution of professions in the research group such broad definitions will suffice.

The participants are often involved in running, acting leader in various situations and/or 
managing companies, which they sometimes also have started themselves $(25 \%)$. However, technological professions are also well represented (23\%) as are Science and Social professions (14\%). By no means does the research group contain only traditionally intellectual professions but also more practical and aesthetic ones are represented (13\%). A portion are students (14\%) and there are also a percentage of retired and unemployed participants $(10 \%)$. One percent of the research group had multiple professions.

Table 3 about here

\section{Work satisfaction}

Of the entire research group of 287 individuals, 225 rated the items of the Work and Life Attitudes Survey (Warr, Cook \& Wall, 1979). Students, the retired and the currently unemployed correctly ignored the inventory. The average score for all 11 items of $M=4.8$, must be regarded as a fairly bland score suggesting that participants were moderately satisfied with their job. There are no extreme average scores for any of the items (Table 4$)$. The three lowest rated items $(=4.3)$ regards salary, employers' use of their full abilities and chance of promotion. The three highest rated items $(=5.2)$ are having freedom at work, the quality of their co-workers and the amount of responsibility given by the employer. However, the results of the scoring, all taken together, is that as a group the participants would appear somewhat indifferent towards their current job. But there is differentiation in the research group. Some of the participants had really found their haven and 
could think of no better job for the time being. Group differentiation became obvious when having content-analyzed the additional qualitative data (see Table 5).

\section{Table 4 about here}

\section{Table 5 about here}

One professional group seems particularly satisfied with their work. This appears to be participants who run, has started and/or manage a company (see Table 3 above). They account for about $25 \%$ of the studied group. Because of position they have considerable influence on decisions made and their outcomes and also what to direct effort towards and in what direction to develop. The fact that such members of the workforce, gifted or not, are generally satisfied with their job is consistent with the literature. The farther away you are from being able to influence your situation and position the more likely it becomes to develop alienation (cf. Locke, 1984). So, not everyone in the group was dismayed, felt unchallenged or alienated. Some did indeed state that enthusiastically that "my job is as if it was made for me. I love it!" or "I am listened to, and my suggestions are taken seriously more so than others". 
However, for the rest of the participants work was not as Self-fulfilling. It was rather something acceptable at best or something which slowly undermined their self-worth at worst, in the end forcing them to seek another job. Limited work satisfaction because of limited or unsuitable tasks haunted them. The speed and efficiency by which intellectually gifted individuals are able to solve problems and manage given tasks became a problem: "I am only partly engaged in my work situation, more detached. It has been long since I used my brain at work", and "simple and tedious tasks. Improvement is not allowed". They have no use for their considerable capacity, or alternatively it is entirely ignored: "The employer has no demand on achievement." The lack of any kind of challenge is a problem for this group.

Limited work satisfaction because of unsuitable management also presents a problem to intellectually gifted individuals. Their type of work may well suit them, but if the management does not know how to "get the best out of his/her employee" because they are so much more different than most of the others in the workforce, the gifted employee runs into trouble: "I have a job in which my entire technical skill is not taken advantage of" and "I feel hindered to use my potential. Probably I am considered too young”. However, it may also be that the organizational structure as such, because of its formal and bureaucratical nature, becomes an obstacle to flexible and creative minds: "The work is good, but the organization is so inflexible. It is so frustrating" and "bureaucrasy can destroy any sunny day."

A related problem is being forced into teams of co-workers where there is a difference in capacity to understand, process tasks and identifying and solving problems. The intellectually gifted individual understands cause and effect much better than most others and can often also see solutions to problems yet undetected by others: "You are dependent on others understanding what you say. Sadly that limits the possibilities" and "working as civil servant is not always easy since the politicians in charge often lack the insight". No one likes to stand out as less competent, especially not the management: "My boss' is not so competent". In short, the lesser competence 
and ability of co-workers and management becomes a problem to the intellectually gifted individual, and no doubt for his or her management and co-workers also.

Some of the researched group had more or less resigned psychologically from their current job but stayed on for various reasons anyway: "The only reason I am still here is not the job as such, but my colleagues whom I like" and "I'm OK with my work. Intellectual stimulation I find outside of work".

\section{Discussion}

While the intellectually gifted participants of this study tended to be highly educated and have chosen to mainly pursue careers in Technology, Science and Social Work, Practical and Aestethic work, their enthusiasm as defined by work satisfaction (Warr, Cook \& Wall, 1979), is anything but overwhelming. They appear accepting but also indifferent in most cases. The additional qualitative analysis of the free responses answers the question why this is the case: they need to do things that they find meaningless and challenging, but they were ignored or misunderstood and their employers did not know how to manage someone gifted. In addition, the research group were often forced to work with others who were less competent and insightful, which slowed everything down and limited the possibilities as seen by the gifted individual.

Only one subgroup of the entire research sample stood out as entirely contrary, namely the entrepreneurs and the managers in leading positions in various types of organizations. They were very satisfied and felt fulfilled and productive.

It is not difficult to understand which the main difference is between the barely satisfied and merely accepting circumstances and the very satisfied embracing their job, namely the degree of experienced challenge, freedom and variety. These are likely to differ substantially depending on where in an hierarchical organization they work. These three are unavoidable related to the socalled Job Characteristics Model (Oldham, 1996); aspects of work known to make possible a 
positive, productive and satisfying work situation: a) skill variety; b) task identity; c) task significance; d) task autonomy and e) task feedback. This comparison suggests strongly that the problem is not likely to be the gifted individual as such but rather that the problem often lies with the organizational cultures.

Unlike Teoh and Quah (1999), who suggests that the keys to make possible especially intellectually gifted individuals future professional success lie in their training and preparation for a career, I suggest that factors determining success, however this is defined, rather lie with others such as future employers. You need to be allowed to be gifted to excel, and if working and staying in an organization only its management can provide the freedom, challenge and variety for the intellectually gifted to fully make his or her contribution to productivity. Managers who make remarks like "why do we hire these intellectuals? They're no damned use. They don't fit in. They cause trouble" (as quoted in Streznewski, 1999; p. 132) are more likely to express ignorance rather than informed managerial leadership.

The world of Science; a career choice that would be quite natural to make for many intellectually gifted individuals, is by no means void of mismanagement (Bennich-Björkman, 1997). Shekerjian (1990) concludes that the scientific world certainly is no exception from ignoring or even harassing its own highly talented members; especially members who distance themselves away from mainstream research and knowledge, even criticize it because they suspect, or have perhaps already found, that alternative explanations are better than the established ones. The difficulty in attracting attention and acceptance for new, and often probably better, ideas and testable theories, is infamously difficult (Segerstråle, 2000). The resistance of scientists to change their minds from the old and to the new, even in the face of convincing evidence contrary to their convictions, has even been termed cognitive conservatism by Greenwald (1980), and is understood by him as a defense mechanism proper. Though, some are prone to resist change more than others (Johnson, et al., 1988). There will always exist an inherent resistance to anyone who might have the 
potential to outdo others (see Persson, in press).

A practical proposition as a result of this study - but preferably on a much larger basis than this single study-- would be to suggest a new and additional development of the Gifted Education agenda: While Gifted Education has been entirely devoted to school systems thus far, it is perhaps paramount to also enlighten the corporate world of leadership and management on giftedness and educate them how to manage their gifted employees. Note that the world of management has realized how important expertise (giftedness/talent) is for development and that the world is becoming increasingly more dependent on knowledge. They have therefore coined the term intellectual capital defining knowledge as a commodity (Stewart, 1999). However, this recognition of individuals who carry quantifiable "know-how" is little interested in the socio-emotional determinants of the work environment which would allow the expert to excel. No individual fares well in a rationalized society to be treated as "commodity", but the gifted are perhaps more sensitive to it than most others (cf. Persson, 2007). I am therefore convinced that management will need to particularly include how to best take responsibility for providing for their gifted and talented workforce also. The investment in time and money to do this would surely benefit the company, the organization as well as the intellectually gifted individual. 


\section{Acknowledgements}

For this research I am indebted to a number of individuals who have willingly assisted me as well as offered their expert knowledge and experience in both setting up the research as well as reading and commenting on the reported results. I extend my thanks to Robert Mallander; Erik Aludden; Björn Liljeqvist and Lars Narvselius_-all representing Mensa Sweden. I also wish to acknowledge the input and assistance of Magnus Blom and Johan Malmqvist both at Jönköping University and of Ray Blakemore, The Netherlands and Rainer Stratkotter, Canada—both of whom belong to most gifted individuals I have ever met. My sincere thanks. 


\section{References}

Adler, M. (1985, March). Stardom and talent. American Economic Review, 75(1), 208-212.

Arnold, K. B. (1995). Lives of promise. What became of high school valedictorians. A 14-year study of achievement and life choices. San Fransisco, CA: Jossey-Bass.

Bennich-Björkman, L. (1997). Organising innovative research. The inner life of university departments. Oxford, UK: Pergamon.

Gagné, F. (1993). Constructs and models pertaining to exceptional human abilities. In K. A. Heller, F. J. Mönks, \& A. Harry Passow (Eds.), International Handbook of Research and Development of Giftedness and Talent (pp. 69-88). Oxford, UK: Pergamon.

Greenwald, A. G. (1980). The totalitarian ego: fabrication and revision of personal history. American Psychologist, 7, 603-618.

Hamlen, W. A. Jr. (1991, November). Superstars in popular music. Empirical evidence. The Review of Economics and Statistics, 73(4), 729-733.

Johnson, J. A., Germer, C. K., Efran, J. S., \& Overton, W. F. (1988). Personality as the basis for theoretical predilections. Journal of Personality and Social Psychology. 55(5), 824-835.

Lewis, M. (1997). Reflections on success. Famous achievers talk frankly to Martyn Lewis about their route to the top. Harpenden, Hertfordshire (UK): Lennard Publishing.

Locke, E. (1984). Job satisfaction. In M. Gruneberg \& T. Wall (eds.), Social psychology and organizational behaviour (pp. 93-117). London: John Wiley \& Sons Ltd.

Oldham, G. R. (1996). Job design. In C. L. Cooper \& I. T. Robertson (eds.), International Review of Organisational and Industrial Psychology (pp.33-60). Chichester, UK: Wiley.

Persson, R. S. (in press). The unwanted gifted and talented. A socio-biological perspective of the societal functions of giftedness. In L. Shavinina (ed.), International handbook of giftedness.

Dordrecht, NL: Springer Science.

Persson, R. S. (2006). VSAIEEDC - a cognition-based generic model for qualitative data analysis in giftedness and talent research. Gifted and Talented International, 21(2), 29-37.

Persson, R. S.(2007). The myth of the anti-social genius. A survey study of the socio-emotional aspects of High-IQ individuals. Gifted and Talented International, 22(2), 19-34.

Ritzer, G. (1992). The McDonaldization of society. Thousand Oaks, CA: Pine Forge Press.

Schlosser, G. A. (2001). Stories of success from eminent Finnish women: a narrative study. High Ability Studies, 12(1), 61-88.

Segerstråle, U. (2000). Defenders of the truth. The battle for science in the sociobiology debate and beyond. New York: Oxford University Press. 
Shaughnessy, M. F., \& Manz, A. F. (1991). Personological research on creativity in the performing arts and fine arts. European Journal for High Ability, 2, 91-101.

Shekerjian, D. (1990). Uncommon genius, How great ideas are born. New York: Viking. Statistics Sweden. (2007). Befolkningens utbildning: Befolkningens utbildningsniva $16-74$ år [The Education of the Swedish Population: Level of education for the 16 to 74-year olds] http:// www.scb.se/UF0506 [Read July $\left.10^{\text {th }} 2007.\right]$

Stewart, T. A. (1999). Intellectual capital. The new wealth of organizations. London: Nicholas Brealey Publishing.

Streznewski, M-L., K. (1999). Gifted grownups: the mixed blessings of extraordinary potential. New York: John Wiley \& Sons, Inc.

Teo, C. T., \& Quah, L. M. (1999). The knowledge, volition and action programme in Singapore: the effects of an experimental intervention programme on high ability achievement. High Ability Studies, 10(1), 23-35.

Van der Heijden, B. I. J. M. (2000). The development and psychometric evaluation of a multidimensional measurement instrument of professional expertise. High Ability Studies, 11(1), 9-40.

Warr, P., Cook, J., \& Wall, T. (1979). Scales for measurement of some work attitudes and aspects of psychological well-being. Journal of Occupational Psychology. 52, 129-148.

Wilms, D. (1986). Patron's opening address. In A. J. Cropley, K. K. Urban, H. Wagner and W. Wieczerkowski (eds.). Giftedness: a continuing worldwide challenge (pp. 16-20). New York: Trillium Press.

Yewchuk, C., Äystö, S., \& Schlosser, G. (2001). Attribution of career facilitators by emininent women of Canada and Finland. High Ability Studies, 12(1), 89-112. 


\section{Demographics}

\section{Appendix 1: Questionnaire}

1. Which is your gender?

Male

Female

2. Which is your age?

years

3. Which is your intelligence level (the score you received when tested for the Mensa membership). If tested with Stanford-Binet please provide your IQ score. If tested with any other test, please provide your percentile.

$\begin{array}{ll}\text { (Stanford-Binet) } & \mathrm{IQ} \\ \text { (Percentil) } & \%\end{array}$

4. What kind of education or training do you have (you may tick more than one if appropriate)?

University degrees $\quad(\mathrm{PhD})$

$$
\begin{aligned}
& \text { (MA, Med, MSc) } \\
& \text { (BA, Bed, BSc) }
\end{aligned}
$$

Professional academic training

(Engineer, Economist, Medical Doctor)

Professional artistic training (Drama,

Music, Visual Arts)

Other training, describe which

No training or education beyond

the compulsory school and high school

5. Which is your profession?

I work as ... (provide your work title)

Currently unemployed

None

I am a currently a student

Work satisfaction

1. The freedom to choose your own method of working (tick only one box)

I am extremely dissatisfied

I am very dissatisfied

I am moderately dissatisfied

I am not sure

I am moderatley satisfied

I am very satisfied

I am extremely satisfied 
2. Your fellow workers (tick only one box)

I am extremely dissatisfied

I am very dissatisfied

I am moderately dissatisfied

I am not sure

I am moderatley satisfied

I am very satisfied

I am extremely satisfied

3. The recognition you get for good work (tick only one box)

I am extremely dissatisfied

I am very dissatisfied

I am moderately dissatisfied

I am not sure

I am moderatley satisfied

I am very satisfied

I am extremely satisfied

4. Your immediate boss (tick only one box)

I am extremely dissatisfied

I am very dissatisfied

I am moderately dissatisfied

I am not sure

I am moderatley satisfied

I am very satisfied

I am extremely satisfied

5. The amount of responsibility you are given (tick only one box)

I am extremely dissatisfied

I am very dissatisfied

I am moderately dissatisfied

I am not sure

I am moderatley satisfied

I am very satisfied

I am extremely satisfied

6. Your rate of pay (tick only one box)

I am extremely dissatisfied

I am very dissatisfied

I am moderately dissatisfied

I am not sure

I am moderatley satisfied

I am very satisfied

I am extremely satisfied 
7. Your opportunity to use your abilities (tick only one box)

I am extremely dissatisfied

I am very dissatisfied

I am moderately dissatisfied

I am not sure

I am moderatley satisfied

I am very satisfied

I am extremely satisfied

8. Your chance of promotion (tick only one box)

I am extremely dissatisfied

I am very dissatisfied

I am moderately dissatisfied

I am not sure

I am moderatley satisfied

I am very satisfied

I am extremely satisfied

9. The attention paid to suggestions you make (tick only one box)

I am extremely dissatisfied

I am very dissatisfied

I am moderately dissatisfied

I am not sure

I am moderatley satisfied

I am very satisfied

I am extremely satisfied

10. The amount of variety in your job (tick only one box)

I am extremely dissatisfied

I am very dissatisfied

I am moderately dissatisfied

I am not sure

I am moderatley satisfied

I am very satisfied

I am extremely satisfied

11. Considering everything - how do you feel about your job? (tick only one box)

I am extremely dissatisfied

I am very dissatisfied

I am moderately dissatisfied

I am not sure

I am moderatley satisfied

I am very satisfied

I am extremely satisfied 
12. Comment briefly and generally on how you experience your job/profession. 
Table 1. Educational background of the Mensa research group $(N=287)$.

Type of training $\quad \%$

University degree $(\mathrm{PhD}$ or equivalent) $\quad 4.9 \%$

University degree (Masters degree) $28.9 \%$

University degree (Bachelor degree) $\quad 17.4 \%$

Professional training program (engineer,

economist, psychologist, teacher and so on) $\quad 19.9 \%$

Artistic training (theatre, music, arts, dance) $\quad 3.1 \%$

Other kind of training (undefined) $\quad 10.5 \%$

No training beyond secondary school $\quad 15.3 \%$ 
Table 2. Educational background of the Mensa research group: Individuals with multiple degrees and/or several types of training $(n=62)$.

\section{Type of training}

$\mathrm{PhD}$ or equivalent + Masters degree

$\mathrm{PhD}$ or equivalent + Professional training

$\mathrm{PhD}$ or equivalent + Artistic training + Other

$\mathrm{PhD}$ or equivalent + Masters degree + Bachelor degree

+ Professional training + Artistic training + Other

Master's degree + Bachelor degree

Master's degree + Professional training

Master's degree + Bachelor degree + Professional training

Master's degree + Bachelor degree + Artistic training

Master's degree + Bachelor degree + Professional training

+ Other

Bachelor degree + Professional training

Bachelor degree + Artistic training

Bachelor degree + Professional training + Other

Bachelor degree + Other

Professional training + Artistic training

Professional training + Other

Professional training + Artistic training + Other

Artistic training + Other

\section{frequency}

3

3

1

1

9

14

4

1

2

9

3

1

2

1

6

1 
Table 3. Types of professions or full-time occupations in the Mensa group $(N=287)$

$\%$

Technology

Information Technology

15

Engineering

$8 \quad \Rightarrow \quad 23$

Science and social work

Healthcare/Medicine

$$
3
$$

Academic/Science

Social work /Communication

10

$1 \quad \Rightarrow \quad 14$

Running, starting and managing companies

Entrepreneurs

$\begin{aligned} 4 & \\ 21 & \Rightarrow\end{aligned}$

Administration/Management

$21 \rightarrow 25$

Practical and aesthetic work

Manual labour

11

Artistic professions

$2 \quad \Rightarrow \quad 13$

Multiple professions

$1 \quad \Rightarrow \quad 1$

Studying

Student + entrepreneur

Students

$\begin{array}{rll}2 & & \\ 12 & \Rightarrow & 14 \\ 10 & \Rightarrow & 10\end{array}$

Retired or unemployed 
Table 4. The mean ratings of participants $(N=225)$ on the Work and Life Attitudes Survey (Warr, Cook \& Wall, 1979). Note that items were scaled from 1 (I am extremely dissatisfied) to 7 (I am extremely satisfied) with 4 being the middle choice (I am not sure).

\begin{tabular}{|c|c|c|c|}
\hline Items & Mean & Median & $\mathrm{SD}$ \\
\hline 1. The freedom to choose your own method of working & 5.2 & 6 & 1.4 \\
\hline 2. Your fellow workers & 5.2 & 6 & 1.1 \\
\hline 3. The recognition you get for good work & 4.7 & 5 & 1.5 \\
\hline 4. Your immediate boss & 4.8 & 5 & 1.5 \\
\hline 5. The amount of responsibility you are given & 5.2 & 6 & 1.4 \\
\hline 6. Your rate of pay & 4.3 & 5 & 1.5 \\
\hline 7. Your opportunity to use your abilities & 4.3 & 5 & 1.6 \\
\hline 8. Your chance of promotion & 4.3 & 5 & 1.6 \\
\hline 9. The attention paid to suggestions you make & 4.8 & 5 & 1.5 \\
\hline 10. The amount of variety in your job & 4.8 & 5 & 1.6 \\
\hline 11. Considering everything - how do you feel about your job? & 5.0 & 5 & 1.3 \\
\hline
\end{tabular}


Table 5. Resulting categories and typical statements as resulting from a content analysis of qualitative comments made by participants in relation to work satisfaction.

\section{Complete satisfaction}

- My job is as if it was made for me. I love it!

- I am given freedom under responsibility. There is acceptance to many alternative solutions.

- I do what I am good at and what I which to do

- I have considerable influence at my work and am in a position to decide my own tasks

- I am listened to, and my suggestions are taken seriously more so than others.

\section{Limited work satisfaction because of unsuitable or non-challenging tasks}

- My work requires no skill and leaves room for no independence. I am resigning.

- I cannot stand routine-like work which demands no effort on my behalf.

- There is not enough to do

- Simple and tedious tasks. Improvement is not allowed.

- Bored. And no possibility to influence my situation at work.

- The employer has no demand on achievement.

- I am not developing enough at my job

- I feel I need more challenge in my job

- I am only partly engaged in my work situation, more detached, It has been long since I used my brain at work.

- I like it but there is not enough for me to do.

\section{Limited work satisfaction because of unsuitable management}

- Bureaucrasy can destroy any sunny day

- My boss should not be a boss. He is incompetent.

- I don't like the job because they force me to do unpaid overtime

- I enjoy my work, but my ideas are never taken seriously.

- The work is good, but the organization is so inflexible. It is so frustrating

- In spite of having a job in the technological field, it is all politics. It is frustrating.

- I feel hindered to use my potential. Probably I am considered too young.

- I have a job in which my entire technical skill is not taken advantage of

- My competence is not used here

- To be a medical doctor means you are the slave of your employer

\section{The unequal competence conflict}

- Colleagues are nice, but often somewhat incompetent

- I am happy with my job, but not so much with my colleagues

- You are dependent on others understanding what you say. Sadly that limits the possibilities

- I really enjoy working with other smart colleagues, not with the not so smart ones.

- My boss' is not so competent

- Working as civil servant is not always easy since the politicians in charge often lack the insight

\section{Resignation and alienation at work}

- I enjoy my work if I get my four cups of coffee a day

- I have no understanding that something should be perfect, therefore I can stand most things

- I am looking for another job

- The only reason I am still here is not the job as such, but my colleagues whom I like.

- I'm OK with my work. Intellectual stimulation I find outside of work 